\title{
Improving Efficiency and Reliability of Protection System of Tarbela Power Station
}

\author{
Muddasar Nawaz ${ }^{1}$,Dr.FarhanZulfiqar ${ }^{2}$, Dr. Mohammad Bilal ${ }^{2}$ and Akif Zia Khan². \\ ${ }^{1}$ Student of Centre of Energy system NUST University, Islamabad, Pakistan. \\ ${ }^{2}$ Lecturer in Centre of Energy System NUST University, Islamabad, Pakistan.
}

\begin{abstract}
Protective relaying system plays a vital role in ensuring the proper and smooth functioning of the Power plant. As the generator is the most expensive part of the plant that's why the provision of a healthy protection system is must. Protection system guarantees the reliability and safe operation of the plant and is called the brain of the power system. Tarbela is the largest power plant of Pakistan and considered as a back bone of power system of Pakistan. In this paper, the generator protective relay of Tarbela power plant is tested and their results are presented. All the protective relays of Tarbela Power Plant are of electromechanical types which were manufactured in 1970-80. Setting, calculation and test result of these relays were then analyzed and recommendation is made for improving the reliability of the protection system of the said plant. Features of new numerical relays and comparison with the installed relays are also presented and finally the description of upgradation/retrofitting of installed electromechanical relay are discussed for smooth transition to new technology.
\end{abstract}

\section{Introduction}

Pakistan is facing major energy crisis now a days. In these circumstances availability of existing installed power plants is very important. Tarbela power plant has an installed of $3478 \mathrm{MW}$ which will be enhanced to $6300 \mathrm{MW}$ in near future.

Protective relays provide a vital role in the power system as it ensures the safety of the electrical equipment [1]. Main function of relay is to detect the faulty part the equipment selectively and initiate command for the quick isolation of that apparatus. The main objective of the protection system is to only isolate the faulty equipment and thus maintain the continuity of power from the other equipment. That's why protection system is called the brain of the power system.

\section{Background}

In Tarbela power plant all the protective relays are of electromechanical types which were manufactured in 1970-80's. All the generator protective relays were tested for checking the response and recommended for the possible solution for improving the reliability of the power plant.

This system is divided into three main components.

-Instrument Transformer

-Protective relays

- Circuit Breaker

Instruments transformer first step down the voltage and current level to predetermined value for the protection relays. From these voltage and current protection calculates or senses the fault and initiate the trip by ordering to circuit breaker which breaks the current path of the faulty circuit [2].

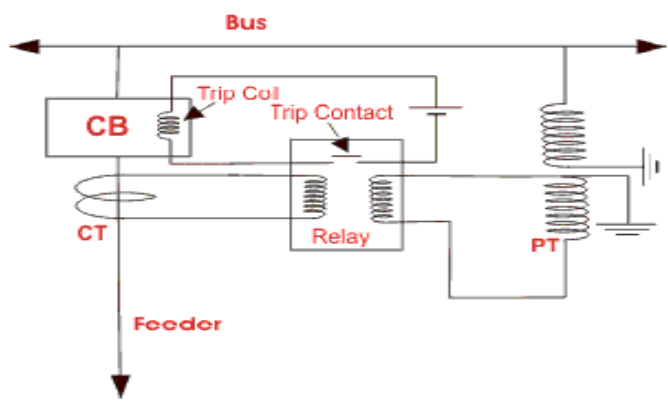

Figure1.Basic Diagram of Protection System

\section{Calculations of secondary values}

Principal Data of Generating Unit: Power=175MW (10 Units) and 432MW (4 Units)

Rated Voltage: $13.8 \mathrm{KV}$

Power factor: 0.85 of Unit 01-04

First the primary current of tarbela Unit is calculated as:

$$
\begin{aligned}
& \text { Power }=\sqrt{3} \mathrm{~V} \text { I } \cos \emptyset(1) \\
& 175 \times 10^{6}=\sqrt{3} \times 13.8 \times 10^{3} \times 0.85 \\
& I_{p}=8614 \mathrm{~A}(2)
\end{aligned}
$$


CT ratio: $12000 / 1$

The rated secondary current will be $=I_{s}=8614 / 12000=0.7178 \mathrm{~A}(3)$

PT ratio: $14400 / 120 \mathrm{~V}$

The rated voltage at secondary side is $=$

$$
V_{s}=\frac{V_{p}}{\text { Pt ratio }}=\frac{13800}{120}=115 \mathrm{~V}(4)
$$

\section{Testing of generator protective relay}

The testing of protective relays is very essential as protection works only in abnormal/fault condition. If there is any internal fault in the electromechanical relay, this defect cannot be detected until the occurrence of the system fault. So periodic maintenance testing should be carried out at least once a year.

The purpose of this test is to check whether the protection system from the relay input terminal onwards working properly or not. This can be done by applying the voltage or current from the test set to the relay terminal and check the relay contacts for alarm/trip signal. This test is known as secondary injection testing.

\subsection{Generatorovervoltage relay}

This protection is provided with the generator for the excessive voltage generated due to some problem in the generator exciter (AVR) or due to over speeding of the generator after the load rejection. Hydroelectric generator may go to $150 \%$ or more of rated speed when the full load is rejected and thus voltage reach to up to a very high level. This overvoltage can damage the insulation of the generator winding if sustained.

For Overvoltage protection, Protective relay is only fed with generator voltages through generator potential transformer. Relay constantly monitor the generator voltage and initiate trip in case of overvoltage. For overvoltage protection the general setting of voltage is between $105 \%-120 \%$. In our case the setting is $112.5 \%$ which is $15.525 \mathrm{KV}$.

The primary rated voltage is: $13.8 \mathrm{KV}$ and secondary side $: V_{s}=115 \mathrm{~V}$

\section{Test Result:}

\begin{tabular}{|l|l|l|}
\hline Sr.No. & Voltage Injected & Time $(\mathrm{sec})$ \\
\hline 01 & $135 \mathrm{~V}$ (Pickup) & $15.5 \mathrm{sec}$ \\
\hline 02 & $202.5 \mathrm{~V}$ & $8.00 \mathrm{sec}$ \\
\hline 03 & $270 \mathrm{~V}$ & $5.00 \mathrm{sec}$ \\
\hline 04 & 337.8 & $2.40 \mathrm{sec}$ \\
\hline
\end{tabular}

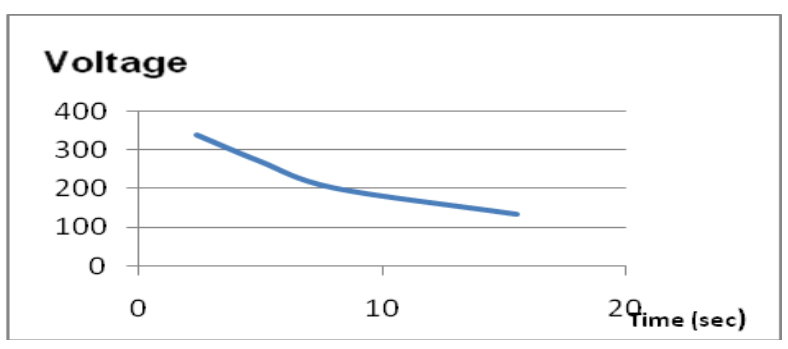

Figure2. Graph of Pickup Voltage Vs Time
The result of this relay reveals that the overvoltage relay is operating almost linear with the time rather than time inverse characteristics. It will be better to use the time inverse response relay as if the voltage increases rapidly; it should trip the generator instantaneously.

\subsection{Generatordifferential protection}

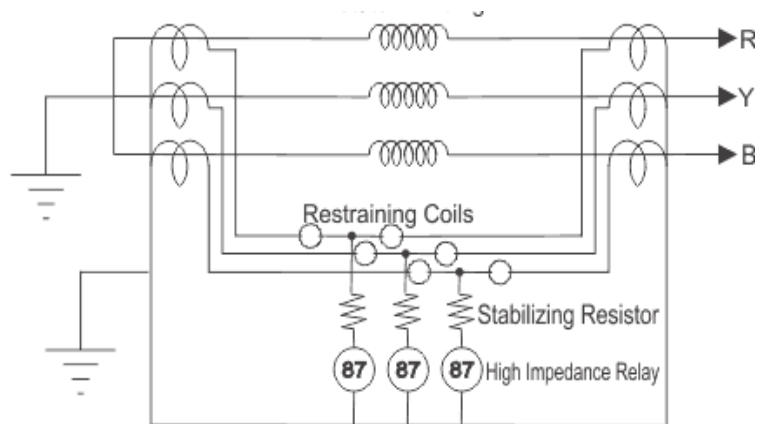

Figure3. Differential Relay CT connections

Differential is the main protection of the generator stator winding internal fault. The input of this protection relay consists of two sets of CT's. One CT set is installed on Generator output side and other on the neutral side. In normal condition the current on the both side of the generator is equal. If there is any mismatch in the current due to internal fault of the winding, the relay detects the difference between the current and then emits the trip command.

The recommended setting for this relay is $10 \%$ difference of rated current.

\section{Test Results}

\begin{tabular}{|l|l|l|l|}
\hline Phase. & $\begin{array}{l}\text { Current } \\
\text { Injected }\end{array}$ & $\begin{array}{l}\text { Current } \\
\text { injected }\end{array}$ & Time(msec) \\
\hline$R$ & $103 \mathrm{~mA}$ & $200 \mathrm{~mA}$ & 432 \\
\hline $\mathrm{Y}$ & $102 \mathrm{~mA}$ & $200 \mathrm{~mA}$ & 405 \\
\hline $\mathrm{B}$ & $102 \mathrm{~mA}$ & $200 \mathrm{~mA}$ & 523 \\
\hline $\mathrm{R}$ & $298 \mathrm{~mA}$ & $200 \mathrm{~mA}$ & 521 \\
\hline
\end{tabular}

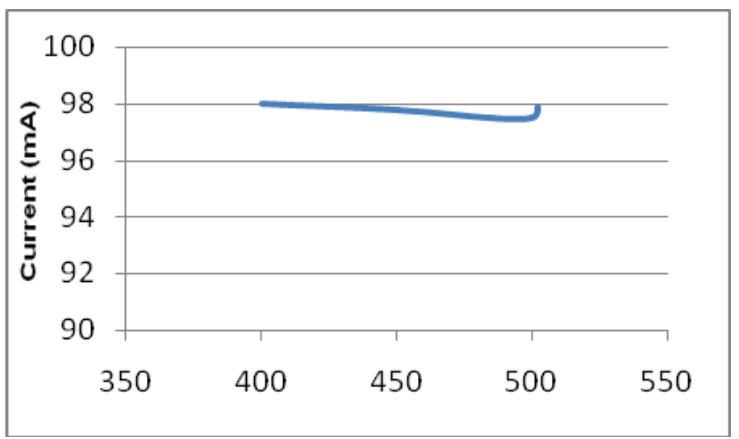

Figure 4. Pickup Current vs Time (milli second)

In the differential relay testing, $200 \mathrm{~mA}$ was injected from the both current sources then the magnitude of the current of one side is slowly decreased and the relay operated when the difference was about $98 \mathrm{~mA}$. This electromechanical has a drawback. If there is a fault in the Red phase only, it will initiate the trip command, but there is no flag installed in the relay which tell the operator about the problem of the exact phase. So testing of the 
generator and protection circuit of all the three phases instead of one will be very time consuming.

\subsection{Negative phase sequence}

This relays detect the unbalancing load of the generator. The three phase power system is symmetrical in normal condition. When a fault occur on the power system, it will become unsymmetrical thus cause unbalance flow of current will cause the excessive temperature of the generator and undesired condition. This relay detects this undesired condition through the input current from the CT and initiate the trip.

The setting for the unbalance load is $7 \%$ for alarm and $20 \%$ for tripping.

\section{Test Result:}

\begin{tabular}{|c|c|c|l|}
\hline R-phase & Y-phase & Blue-phase & Time(sec) \\
\hline $1.94 \mathrm{~mA}$ & 0 & 0 & $4.06 \mathrm{sec}$ \\
\hline 0 & $1.90 \mathrm{~mA}$ & 0 & $4.5 \mathrm{sec}$ \\
\hline 0 & 0 & $1.99 \mathrm{~mA}$ & $4.00 \mathrm{sec}$ \\
\hline $3.99 \mathrm{~mA}$ & $2.0 \mathrm{~mA}$ & $2.0 \mathrm{~mA}$ & $3.99 \mathrm{sec}$ \\
\hline
\end{tabular}

\subsection{Generator overcurrent relay}

Generator overcurrent protection protects the generator from overloading and short circuit and other fault which can increase the load on the generator. For this purpose one CT output is connected to a protective relay which is continuously monitoring the current of the generator. If the current level goes up due to any abnormal condition this relay operate and initiate the trip.

The setting of this relay is around $120-150 \%$ of rated current. In our case the relay setting is $140 \%$ approx.

\section{Test Results}

\begin{tabular}{|l|l|l|}
\hline Sr.No. & Current Injected & Time(sec) \\
\hline 01 & 1A (Pickup) & $3.044 \mathrm{sec}$ \\
\hline 02 & $1.5 \mathrm{~A}$ & $2.350 \mathrm{sec}$ \\
\hline 03 & $2.0 \mathrm{~A}$ & $1.340 \mathrm{sec}$ \\
\hline 04 & $2.5 \mathrm{~A}$ & $0.792 \mathrm{sec}$ \\
\hline
\end{tabular}

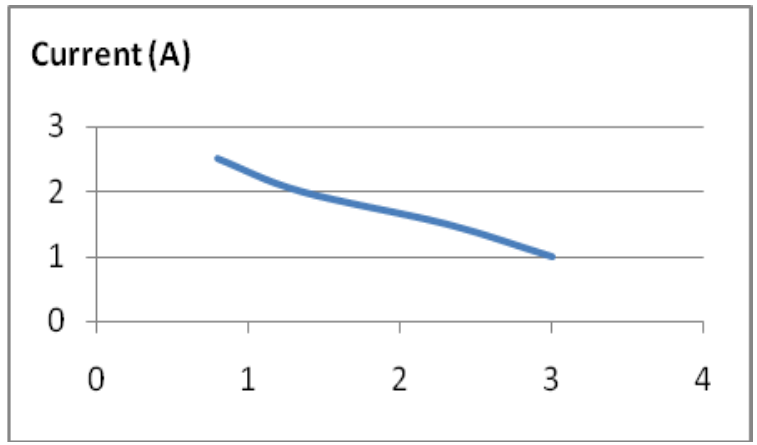

Figure 5. Pickup Current Vs Time(sec)

One overcurrent relay installed in the Unit 04 was tested earlier was found faulty. The disk of the electromechanical relay was moving but don't have the enough force for contact making. The contact resistance was in kilo-ohm. The same defective relay was replaced with this healthy one.

\subsection{Generatorvoltage controlled overcurrent/ generator impedancerelay}

This relay works on the same principal as of distance relay. If a short circuit occurs, the current will increases and voltage suddenly decrease. This relay checks impedance of the system by monitoring both the current and voltage of the system. This relay works as backup protection of generator. If the ratio of voltage and current drops to a certain value this relays operates and initiate the trip.

Setting of this relay can be calculated as:

$$
\text { Generator impedance }=\frac{V}{l} \times \frac{1}{\sqrt{3}}=\frac{115}{.7178 \times \sqrt{3}}(5)
$$

So Generator Impedance $=92.5 \Omega$

In order to avoid operation of the relay due to the fault on the HV side of the transformer, the setting of this is kept very low. i.e. $12 \Omega$ per phase.

\section{Test Results}

\begin{tabular}{|l|l|l|l|}
\hline Phase & $\begin{array}{l}\text { Voltage } \\
\text { Injected (V) }\end{array}$ & $\begin{array}{l}\text { Current } \\
\text { Injected (I) }\end{array}$ & Time(sec) \\
\hline $\mathrm{R}$ & 40 & 2.11 & 5.01 \\
\hline $\mathrm{Y}$ & 40 & 2.130 & 5.05 \\
\hline $\mathrm{B}$ & 40 & 2.150 & 5.09 \\
\hline $\mathrm{R}$ & 60 & 3.110 & 2.05 \\
\hline
\end{tabular}

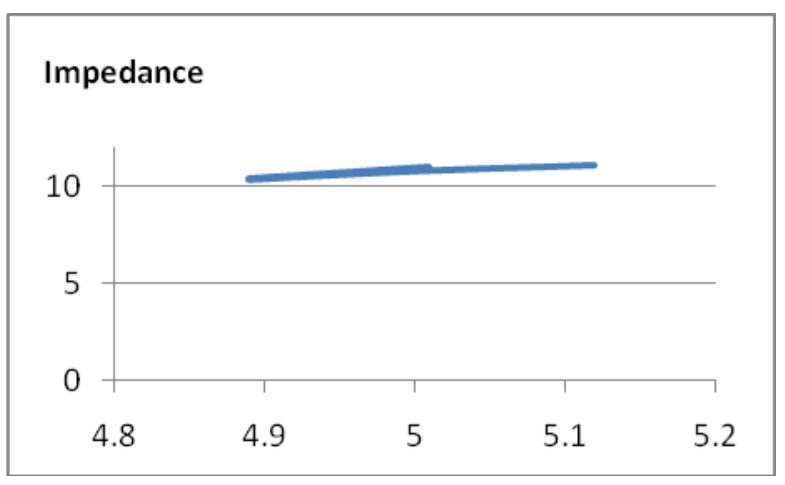

Figure 6. Impedance vs Time(s)

\subsection{Transformer differential relay}

The working principle of generator transformer differential relay is same as of generator differential relay. This relay checks the current of generator neutral and transformer output current. The transformer output current will not match exactly as the generator current. So a matching $\mathrm{CT}$ is used with the protective relay for matching the current of protective relays on both sides. If a fault occurs in the winding of generator or transformer, the matching of the current is disturbed and this relay order for the trip of the generator and transformer. 
Test Results

\begin{tabular}{|l|l|l|c|}
\hline Phase. & $\begin{array}{l}\text { Current } \\
\text { Injected }\end{array}$ & $\begin{array}{l}\text { Current } \\
\text { injected }\end{array}$ & Time(msec) \\
\hline $\mathrm{R}$ & $150 \mathrm{~mA}$ & $301 \mathrm{~mA}$ & 235 \\
\hline $\mathrm{Y}$ & $150 \mathrm{~mA}$ & $301 \mathrm{~mA}$ & 205 \\
\hline $\mathrm{B}$ & $150 \mathrm{~mA}$ & $300 \mathrm{~mA}$ & 245 \\
\hline $\mathrm{R}$ & $250 \mathrm{~mA}$ & $400 \mathrm{~mA}$ & 205 \\
\hline
\end{tabular}

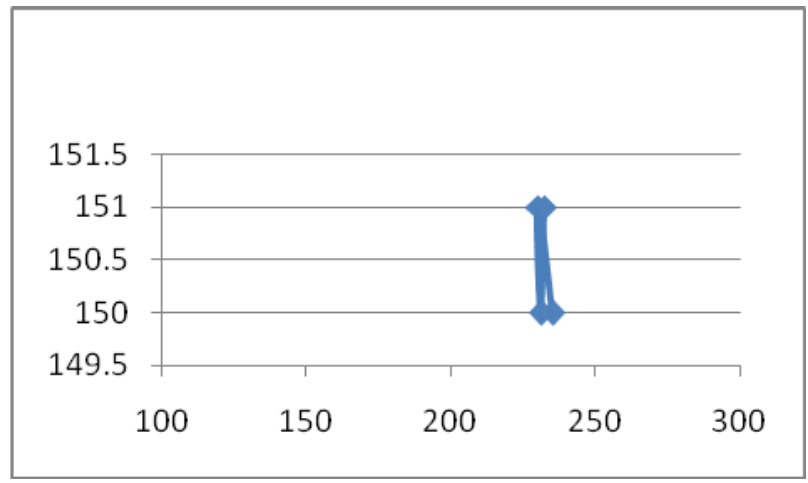

Figure 7.Pickup Current Vs Time

\subsection{Generator antimotoring relay}

This protection is provided with the generator for protecting the generator to run as motor. If the prime mover i.e.the water entering into turbine of the generator fails due to the governor failure or shutdown and the wicket gates of the turbine closes which causes the blockage of water flow to the turbine. As the generator is connected to the power system, for achieving the same frequency of the system the generator will run as a motor and move with the same speed. To avoid this undesired condition Antimotoring relay has been installed. This relay continuously measure the phase angle of the voltage and current, in case of this fault, the direction of flow of current is reverse which is detected by the relay and order the trip command.

The recommended setting for the reverse power relay of hydro electric power plants is $5 \%$ of the rated power.

\section{Test Result}

Voltage injected: $100\left\llcorner 0^{\circ}\right.$

Current injected: $0.4 \mathrm{~A}$

Relay operated (Phase Angle): $90^{\circ}-270^{\circ}$

\subsection{Generator pt balance relay}

This relay checks the generator voltages from the two PT's installed on the same generator. The correct status of the generator voltage is necessary because PT's are used for metering, protection and control of generator voltage. This relay continuously monitors the voltage of the generator and detect if any difference in the voltages of the PT's due to blown fuse or other fault, thus preventing improper function of other equipment which is associated with the PT voltage.

Recommended setting of this relay is $10 \%$ difference in PT's Voltage.

Test Result
\begin{tabular}{|c|c|c|c|}
\hline Phase. & $\begin{array}{c}\text { Voltage } \\
\text { Injected (V) }\end{array}$ & $\begin{array}{c}\text { Voltage } \\
\text { injected (V) }\end{array}$ & $\begin{array}{c}\text { Time }(\mathbf{s e c} \\
\text { ) }\end{array}$ \\
\hline $\mathrm{R}$ & 100 & 90 & 5.044 \\
\hline $\mathrm{Y}$ & 100 & 90 & 5.034 \\
\hline $\mathrm{B}$ & 100 & 91 & 6.008 \\
\hline $\mathrm{R}$ & 100 & 89 & 5.031 \\
\hline
\end{tabular}

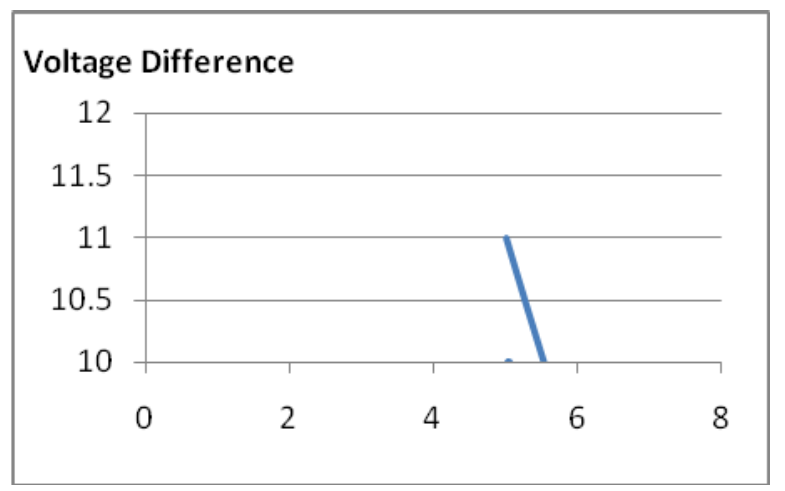

Figure 8.Voltage Difference Vs Time

\section{Upgradationofelectromechanical relays}

For upgradation of protection system, the main equipment to replace is the relays with the new state of the art relays. Other equipment like CT's,PT's, wiring and other allied equipment will be the same if functioning properly.

For upgradation process the most important work is the relay setting and interfacing which includes the old wiring of CT, PT, alarm and breaker trip wires connected to the old relay [4].Before the startup of this activity the wiring of the relays should be carefully checked with drawings because in many cases wiring circuit has been modified and not updated in the drawings. Before the dismantling, properly ferrules/tag the wires again for easy handling of work at later stages.

New Power plants i.e. Ghazi Barotha having a capacity of $1450 \mathrm{MW}$ is also using new state of the art protection system which comprises of numerical relays. Numerical relay are also for protecting the equipment used in transmission and distribution power system. These are multifunction relays having function of protection, metering, control. These relay can have feature of recording the faults and alarms for troubleshooting the fault easily and effectively. New numerical relays have the feature of multipurpose protection. i.e. one relay can monitor all the generator protection. But still it is recommendable to use two numerical relays for the generator protection of onegenerating unit. And both these relays must have a redundant processor and power supply which will increase the protection level to a very high level.

Electromechanical relays can be replaced with the numerical relays after setting, programming and testing of the parameters of new relay. The new relays require less space and wiring as compared to the older one as only one relay can perform all the protection functions. 


\section{Conclusion}

The tested relay of Tarbela power station didn't show linear and stable response. The protection system installed in the power plant is no more reliable and efficient. Because the relay installed are of electromechanical type which were manufactured in the 70 's. The burden of these electromechanical relays is very high thus causing extra burden on the current and potential transformer.

These relays now need periodic testing and calibration because with the passage of the time the reliability of these relays has been drastically decreased. And too many tests on these relays also effects the performance of these relays. These relays are composed of mechanical switches, springs, linkages which are prone to be weaken. In several occasion these relay generated some internal fault in it and cause a false tripping and thus cause a generation loss to the government.

Moreover these relays provide only a single function. i.e. one relay for one protection while new state of the art one numerical relay can provide all the functions of the generator protection[5]. New numerical relay response is very fast and precise as compared to the mechanical one. And it is more economical to use one relay instead of many[6]. So it is highly recommended to replace these electromechanical relays with the new numerical relays. As numerical relays contains many new features like self supervision and recording of disturbance in the power system.

\section{References}

1. Sykes, J.; Madani, V.; Burger, J.; Adamiak, M.; Premerlani, W., "Reliabilty of protection systems (what are the real concerns)," in Protective Relay Engineers, 2010 63rd Annual Conference for, vol., no., pp.1-16, March 29 2010-April 12010.

2. Tian; Qi-Wei Hu; Yong-Sheng Bai; Yan Tian, "Notice of Retraction Reliability analyses of digital protection relay system," in Quality, Reliability, Risk, Maintenance, and Safety Engineering (QR2MSE), 2013 International Conference on, vol., no., pp.1308-1311, 15-18 July 2013.

3. Wright, S.A.; Kangala, A.; Sahni, M.; Lee, W.J.; Kenarangui, R.; Threlkeld, H.F.; Martinez, M.A., "Benefits of upgrading protection schemes for hydroelectric power plants," in Industrial and Commercial Power Systems Technical Conference, 2005 IEEE , vol., no., pp.218-225, 8-12 May 2005.

4. Sperl, J.; Carper, B.; Coe, W., "Upgrading your protective relays - when theory meets reality," in Protective Relay Engineers, 2010 63rd Annual Conference for, vol., no., pp.1-8, March 29 2010April 12010.

5. Bogdanov, D., "Redundant design of relay protection system for power plant unit with synchronous generator," in Electrical Apparatus and Technologies (SIELA), 2014 18th International Symposium on, vol., no., pp.1-4, 29-31 May 2014.

6. Novak, J.J.; Kirby, R.D., "Better, faster, and more economical integrated protective relaying and control using digital bits and logic," in Petroleum and Chemical Industry Technical Conference, 2008. PCIC 2008. 55th IEEE, vol., no., pp.1-12, 22-24 Sept. 2008 